\title{
Production of High Purity Metals: A Review on Zone Refining Process
}

\author{
Xiaoxin Zhang, Semiramis Friedrich ${ }^{* \#, ~ B e r n d ~ F r i e d r i c h ~}$ \\ IME Process Metallurgy and Metal Recycling, RWTH Aachen University, Aachen, Germany \\ Email: *SFriedrich@ime-aachen.de
}

How to cite this paper: Zhang, X.X., Friedrich, S. and Friedrich, B. (2018) Production of High Purity Metals: A Review on Zone Refining Process. Journal of Crystallization Process and Technology, 8, 3355.

https://doi.org/10.4236/jcpt.2018.81003

Received: November 17, 2017

Accepted: January 20, 2018

Published: January 24, 2018

Copyright $\odot 2018$ by authors and Scientific Research Publishing Inc. This work is licensed under the Creative Commons Attribution International License (CC BY 4.0).

http://creativecommons.org/licenses/by/4.0/

\begin{abstract}
Purification is a primary application of zone melting, in which the improvement of efficiency, production yield and minimum achievable impurity level are always the research focus due to the increasing demand for high purity metals. This paper has systematically outlined the whole development of related research on zone refining of metals including basic theories, variants of zone refining, parametric optimization, numerical models, and high purity analytical methods. The collection of this information could be of good value to improve the refining efficiency and the production of high purity metals by zone refining.
\end{abstract}

\section{Keywords}

Zone Refining, Zone Melting, High Purity, Distribution Coefficient, Aluminium, Germanium, Ultra-Pure Metal

\section{Introduction}

High purity (99.999\% (5N) or more) metals play a key role in current high-tech industrial field, such as special electronics, integrate circuits, photovoltaic systems, optical elements, chemical applications, etc., as in these areas even low concentrations of impurities could completely deactivate the desirable function. Table 1 shows some exemplary applications for selected metals. Besides general applications, high purity metals can also be used as additives to produce high purity alloys and provide the possibility to research on their intrinsic properties. Accordingly, the demand of high purity metals has been increasing with the development of technology and the investment in scientific research. For example, the prices of Germanium metal as well as its primary production increased dramatically during last decade, from 380 dollar/ton in 2002 to 1900 dollar/ton in 2014 and from "ORCID: 0000-0002-4078-0799. 
Table 1. The application of different high purity metallic elements.

\begin{tabular}{clll}
\hline Metal & \multicolumn{1}{c}{ Application } & Metal & \multicolumn{1}{c}{ Application } \\
\hline $\mathrm{Al}[1]$ & $\begin{array}{l}\text { Integrated circuits, semiconductor, LCD screen, catalyst } \\
\text { market, optical products, and electronic ceramics }\end{array}$ & $\mathrm{Ga} \mathrm{[2]}$ & $\begin{array}{l}\text { Ga based III-V semiconductor used in electronic and } \\
\text { optoelectronic industries, such as GaAs }\end{array}$ \\
$\mathrm{Ge}[3][4]$ & $\begin{array}{l}\text { Radiation detector, infrared devices, fiber optic, infrared } \\
\text { device, semiconductors, Catalyst }\end{array}$ & $\mathrm{In}[2]$ & $\begin{array}{l}\text { In based III-V semiconductor used in electronic and op- } \\
\text { toelectronic industry, such as InP }\end{array}$ \\
$\mathrm{Sb}[5]$ & $\begin{array}{l}\text { Semi-conductor devices for crystal doping, photocell } \\
\text { cathodes }\end{array}$ & $\mathrm{Te}[6]$ & $\begin{array}{l}\text { compounds Semiconductor employed in electronic and } \\
\text { optical device, such as CdTe }\end{array}$ \\
$\mathrm{Cd}[5][7]$ & Infrared detector, solders for semi-conductor processing & $\mathrm{Se}[8]$ & II-VI compounds semiconductor \\
\hline
\end{tabular}

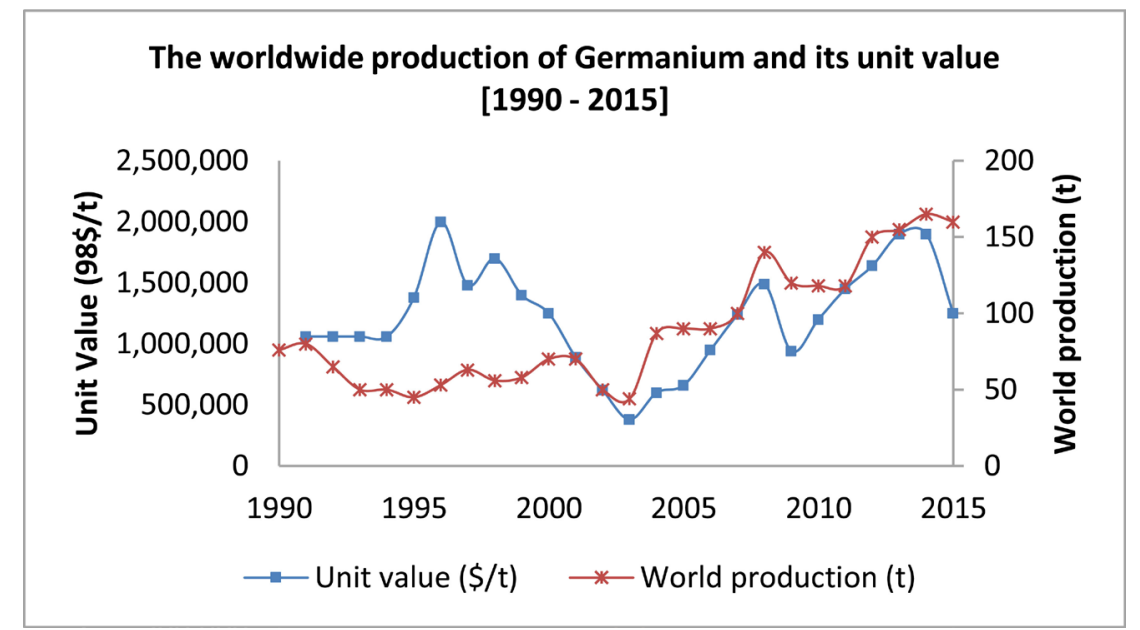

Figure 1. The worldwide production and price of Germanium [9] (Unit value in 1998 U.S. dollars was used as the standard unit value for all years, which was exchanged by the Consumer Price Index conversion factor).

44 tons in 2002 to 165 tons in 2014, respectively, as seen in Figure 1.

In general, to fulfill the need of high purity or electronics-grade materials, a number of methodologies have been investigated including precipitation, crystallization, electrolysis, vacuum distillation, solvent extraction and zone melting, etc. [5]. However, chemical precipitation, electrolysis, and solvent extraction are mainly considered as pre-refining steps as they are accessible to more contaminant resource. Further refinement (e.g. $>4 \mathrm{~N}$ - or $5 \mathrm{~N}$-purity) will be only achieved in combination with other methods, such as vacuum distillation as well as zone refining [5]. However, vacuum distillation can be only applied in systems with significant vapor pressure difference of the base metal in comparison to that of its impurities (e.g. $\mathrm{Mg}, \mathrm{Zn}, \mathrm{Mn}$, etc.). It needs complex construction and expensive pumps to obtain ultra-vacuum. In some exceptional cases such as Te, it makes though sense to combine both methodologies of distillation and zone refining to ascend the purity stepwise (once to $5 \mathrm{~N}$ and then to $7 \mathrm{~N}$ ) [6]. The refined metals through zone refining are typically in the form of polycrystalline structures [10]. Single crystal growing could be performed by zone refining together with zone leveling (homogenous distribution of impurities), which are the two main applications of zone melting [11] [12]. But it is a big challenge to con- 
trol the growing conditions such as nucleation, temperature gradient, thermal strains, etc. Alternatively, other methods like Czochralski (CZ) crystal growth technology [13] and Bridgman-Stockbarger crystal growth technology [14], have been more often used for this purpose.

Zone refining is used extensively to produce high purity final materials since the early 1950s [15] [16]. And a large amount of theories and experience has been generated while producing high purity metals, such as Germanium [17] [18], Tellurium [19] [20], Cadmium [7] [21], Aluminium [22] [23], etc. These include basic mechanism clarification, modification of zone refining set-up, optimization of operation parameters, and numerical simulation, etc. The main task in this paper is systematically outlining the whole development of related research on zone refining of metals including basic theories, variants of zone refining technology, parametric optimization, simulation models, and high purity analytical methods, in order to provide an updated reference to the ongoing research of zone refining of metals.

\section{Zone Refining Mechanism}

Zone melting refining has essentially the same mechanism as for the purification via unidirectional solidification/segregation. The solution of the impurities in one metal is mostly different in liquid or solid state. The ratio of impurities concentration in solid $\left(\mathrm{C}_{\mathrm{S}}\right)$ to that in liquid $\left(\mathrm{C}_{\mathrm{L}}\right)$ is defined as equilibrium distribution coefficient $\mathrm{k}$ (see Figure 2(a)), which approximately keeps a constant while temperature changes between liquidus and solidus. This value could be less or more than one for different impurities, showing the level of difficulty for their removal. The zone melting process is operating practically by a slow unidirectional movement of a liquid zone, or a series of liquid zones, along a solid ingot, as shown in Figure 2(b). As the zone moves, the solid metal ahead of the liquid zone melts at the melting interface of liquid and solid, and the liquid metal solidifies behind at the freezing interface. Thereby, the impurities at the freezing interface will continuously move to the liquid or to the solid (depending on their distribution coefficients). As a result they become concentrated in one or the other end of $\mathrm{Al}$; hence, the rest of the ingot is partially purified. To achieve a desirable purity level, though, many passes should be occurred.

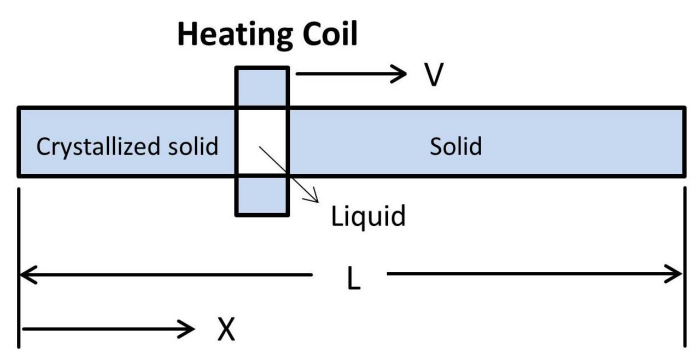

(a)

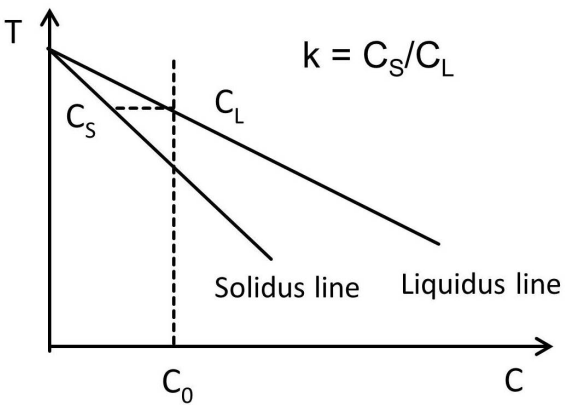

(b)

Figure 2. Scheme of zone refining process (a) and part of binary phase diagram (b). 


\subsection{Basic Equations in Zone Refining}

To analyze the impurities distribution in zone melting in a simple way, following variables are defined.

$$
L=1 ; Z=z / L<1 ; X=x / L \leq 1
$$

where $L$ is the length of the sample; $z$ is the zone length; $Z$ is the normalized zone length; $X$ is the movement distance of the molten zone; $X$ is the normalized movement distance of the molten zone.

The critical important parameters in zone refining are the equilibrium distribution coefficient $\mathrm{k}$ as well as the effective distribution coefficient $k_{\text {eff }} \boldsymbol{k}_{\text {eff }}$ is defined as the experimental $C_{S} / C_{L}$. However, due to the difficulty in getting the experimental $C_{L}$, it can be calculated with the following-so called Burton-PrimSlichter (BPS)—-model and equation:

$$
k_{\text {eff }}=\frac{k}{k+(1-k) \exp (-V \delta / D)}
$$

where $D$ is the impurity diffusion coefficient in the melt, $\delta$ the thickness of the diffusion boundary layer at the solid/liquid interface and $V$ is the molten zone movement velocity. The molten zone movement velocity and diffusion layer thickness are two important parameters which can be altered to affect the $k_{\text {eff }}$ In addition, the thickness of the diffusion layer depends on the convection inside the melt and the melt property itself, such as viscosity, diffusivity of the solute. If diffusion is the only concentration compensation process in the melt, the diffusion layer would be too thick and hence worsen the refinement efficiency. If convection currents are available, $\delta$ is about some millimeters and can be reduced to $0.1 \mathrm{~mm}$ by moderate stirring and to $0.01 \mathrm{~mm}$ by intense stirring [24]. Therefore, low zone movement velocity, intensive convection in the melt, and high diffusion coefficient of impurities in the molten metal will result in a lower $k_{\text {eff }}$ if $k<1$ and a higher $k_{\text {eff }}$ if $k>1$. Regarding that the higher movement velocity would allow more passes of molten zone per unit of time, nevertheless, it should be limited by the constitutional supercooling factor as following [25]:

$$
V \leq \frac{G D k}{m C_{s}(1-k)}
$$

where $G$ is the temperature gradient in the liquid, $C_{S}$ is the impurity concentration in solid at the freezing interface, and $\mathrm{m}$ is the slope of the liquidus line in Figure 2(b). This limit value is the theoretical maximum crystallization velocity (assumed as the zone movement velocity in zone refining) to keep a flat crystallization interface. The appearing of constitutional supercooling when the zone movement velocity is over the limit will give rise to fluctuation in the shape of crystallization interface, e.g. dendrites formation, having a negative influence on refining by entrapping the solute. Therefore, the selection of an appropriate zone movement velocity is of crucial importance in this process [26].

In the case of unidirectional solidification of a melt with a planar liquid/solid interface and considering a simple binary system with liquidus and solidus ap- 
proximating to straight lines as well as assuming the solute diffusion in solid as neglected but in liquid as completed, the solute distribution along the bar was presented by Scheil [27] as

$$
\frac{C_{s}}{C_{o}}=k(1-X)^{k-1}
$$

By comparison, making following assumptions in zone refining process:

- the distribution coefficient $k$ is constant, independent of temperature

- the zone length and travel rate are constant in each pass

- the densities of liquid and solid are the same

- the model regards to one-dimensional analysis

- diffusion of the solute in the solid is negligible and diffusion of solute in the melt is complete

After one pass of a molten zone, Pfann [15] [16] has shown that the composition distribution profile along the bar (except for the last zone length) will be:

$$
\frac{C_{s}}{C_{0}}=1-(1-k) \exp \left(-\frac{k X}{Z}\right) \text { for } 0 \leq X \leq 1-Z
$$

For the last zone length, where the normal freezing takes place, the solute distribution is derived by using of equation (3) as following:

$$
\frac{C_{s}}{C_{0}}=\left\{1-(1-k) \exp \left(-k \frac{1-Z}{Z}\right)\right\} \times\left\{1-\left[\frac{X-(1-Z)}{Z}\right]\right\}^{k-1} \text { for } 1-Z \leq X \leq 1
$$

When the bar is refined through many zone passes, a steady state or ultimate impurity concentration distribution will be attained, at which segregation flux of impurities at freezing interface is always compensated by an equal backward flux at the melting interface throughout the bar. This phenomenon can be illustrated easily by simulation with Spim model, as seen in Figure 3 [28]. As the number of zone passes is increasing, the impurity concentration will be reduced stepwise.

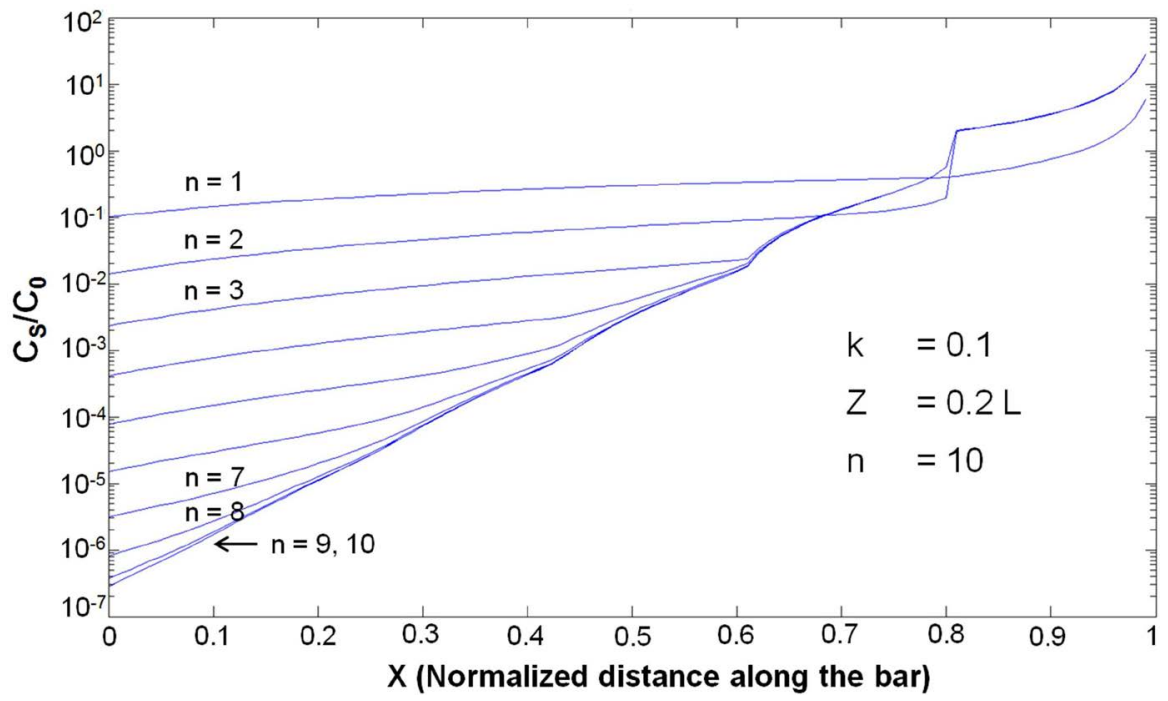

Figure 3. Impurity concentration distribution profiles with increasing number of zone passes simulated with Spim model [28]. 
However, the concentration distribution profile will be stable when the number of zone passes exceeds nine, i.e. the ultimate impurity concentration distribution is achieved. Besides, the ultimate concentration distribution can be represented with a function as following [15] [16]:

$$
c(X)=A \mathrm{e}^{B X}
$$

where $A$ and $B$ are constants and derived from

$$
\begin{aligned}
& k=\frac{B L}{\mathrm{e}^{B L}-1} \\
& A=\frac{C_{0} B L}{\mathrm{e}^{B L}-1}
\end{aligned}
$$

\subsection{Zone Refining Influencing Factors}

The efficiency of zone refining is affected by a variety of experimental factors, which can be altered to optimize the process. These factors include [29] [30]:

1) Effective distribution coefficient $\left(k_{\text {eff }}\right)$, representing the experimental ratio of $C_{S}$ to $C_{L}$. This factor itself (as seen in chapter 2.1) is dependent on the diffusion layer thickness between liquid/solid, movement velocity of the zone, diffusion coefficient of each impurity as well as the heating power.

2) Zone movement velocity, which should be normally kept slow enough to increase the refining efficiency (decrease $k_{\text {eff }}$ for $k<1$ and increase $k_{\text {eff }}$ for $k>1$ ) but at the same time too low velocities increase the time consumption for each pass tremendously. The term refining efficiency refers here to the maximum impurity removal a zone refining process can achieve.

3) Zone length that is the length of the molten zone, affecting both the ultimate distribution of the elements as well as the rate, at which it is achieved. This length is affected by many factors, such as heating power, zone movement velocity, thermal conductivity of crucible and charge, etc.

4) The temperature gradient at the solid/liquid interface, influencing the microsegregation of impurities at that area. This is also controlled by heating power, zone movement velocity, thermal conductivity of crucible and charges, etc.

5) The number of zone passes. Less passes can't attain a product with high purity; however, more passes consume more time.

The experimental optimization of the above mentioned zone refining parameters are not of general use, as they are dependent on the properties of particular systems, such as equipment specifications, specimen diameter, melt viscosity, and the diffusion and distribution coefficients of impurities [28]. Instead, some attempts via simulation methodology have been made to optimize the refining efficiency, presented in chapter 4 and 5.

\section{Design Variants of Zone Refining}

Various zone refining technologies exist based on the same principle. According to the geometry or the way of charging, they could be categorized in four types, 
e.g. horizontal-, vertical-, floating- as well as continuous zone refining (as presented in Figure 4). The details on characteristics, advantages/disadvantages, and application for each type of technology have been summarized in Table 2. Usually, horizontal zone refining is preferred, when zone refining is operated in a crucible. However, it occupies more floor surface in comparison with vertical zone refining. Floating zone refining should be used in those cases, where no crucible can be applied due to the chemically reactive molten phase, such as tungsten, zirconium, iron, etc. Generally zone refining is a very time consuming batch technique, in which the refining efficiency for each single pass decreases when the zone passing number increases. To overcome these disadvantages, continuous zone refining was put forward by applying some special structures to realize the function of refining materials without a break. However, until now, neither any new practical report on that has been published, nor any industrial application has been seen, since it was announced in 1950s-1960s [31] [32] [33].
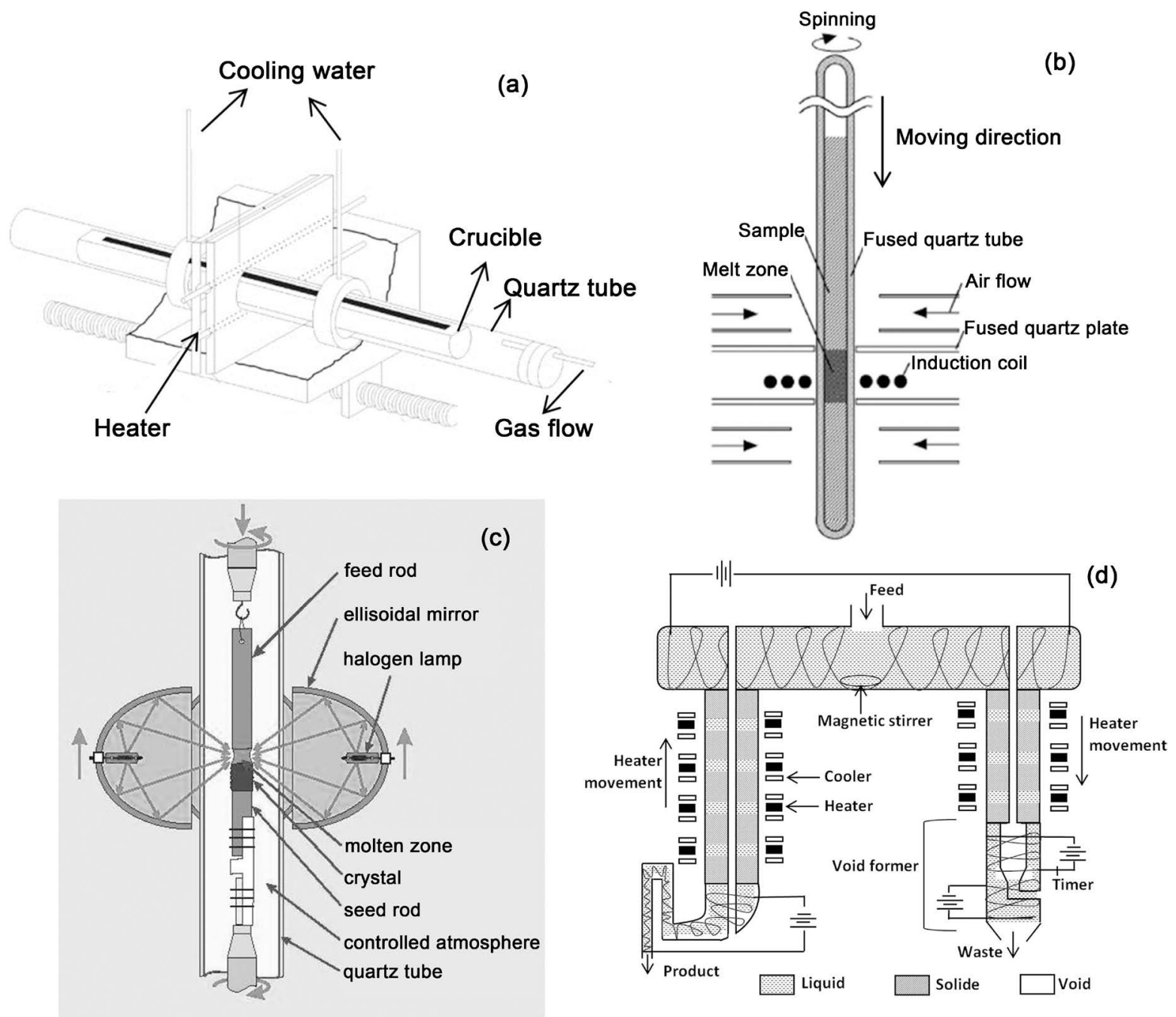

Figure 4. Structure of variable zone refining technologies: (a) Horizontal zone refining [30]; (b) vertical zone refining [34]; (c) floating zone refining [35]; (d) continuous zone refining [33], adapted pictures. 
Table 2. Comparison of different variants of zone refining technology [31] [32] [36].

\begin{tabular}{|c|c|c|c|c|}
\hline $\begin{array}{c}\text { Variants of } \\
\text { zone refining }\end{array}$ & Characteristics & Advantages & Disadvantages & Application \\
\hline $\begin{array}{l}\text { Horizontal } \\
\text { zone refining }\end{array}$ & $\begin{array}{l}\text { Crucible is positioned } \\
\text { horizontally; Heating elements } \\
\text { move horizontally }\end{array}$ & $\begin{array}{l}\text { Easy to load and unload } \\
\text { materials; easily distinguish the } \\
\text { interface }\end{array}$ & $\begin{array}{l}\text { Bulk transport phenomenon; } \\
\text { equipment occupies more } \\
\text { spaces }\end{array}$ & $\begin{array}{l}\text { Most metals, except for } \\
\text { some reactive materials }\end{array}$ \\
\hline $\begin{array}{l}\text { Vertical } \\
\text { zone refining }\end{array}$ & $\begin{array}{l}\text { Crucible is positioned vertically } \\
\text { and heating elements move } \\
\text { vertically }\end{array}$ & Less place occupation & $\begin{array}{l}\text { Not easy to load and unload } \\
\text { materials; more risk on } \\
\text { cracking crucible }\end{array}$ & $\begin{array}{l}\text { Most metals, except for } \\
\text { some reactive materials }\end{array}$ \\
\hline $\begin{array}{l}\text { Floating } \\
\text { zone refining }\end{array}$ & $\begin{array}{l}\text { Without crucible; The material is } \\
\text { positioned vertically; The molten } \\
\text { zone is held by liquid surface } \\
\text { tension }\end{array}$ & $\begin{array}{l}\text { Less contamination resources; } \\
\text { less place occupation; good heat } \\
\text { transfer }\end{array}$ & $\begin{array}{l}\text { Limited charging material } \\
\text { with high surface tension; } \\
\text { Less production due to small } \\
\text { size of material }\end{array}$ & $\begin{array}{l}\text { Reactive metals, such as } \\
\text { silicon, tungsten, zirconium, } \\
\text { iron, etc. }\end{array}$ \\
\hline $\begin{array}{l}\text { Continuous } \\
\text { zone refining }\end{array}$ & $\begin{array}{l}\text { Having feeding inlet and product } \\
\text { and waste outlet; Feed Materials } \\
\text { and get product and waste } \\
\text { continuously }\end{array}$ & $\begin{array}{l}\text { High production; High refining } \\
\text { efficiency }\end{array}$ & $\begin{array}{l}\text { Complicated design; High } \\
\text { cost; Difficulty in operation }\end{array}$ & $\begin{array}{l}\text { Theoretically most metals, } \\
\text { but the development is in } \\
\text { the experimental stage; no } \\
\text { practical results or } \\
\text { commercial use at present }\end{array}$ \\
\hline
\end{tabular}

In addition, to obtain a certain zone length, the zone melting equipment should be provided with a proper heating field. In general an ideal zone refining apparatus should allow the control of short zones with short spacings and consume electrical power economically to heat the materials up to the melting point. Due to consideration of costs, materials properties as well as controlling of desirable zone length, the available heating techniques can include resistance heating, induction heating, electrical discharge or radiation heating. Amongst them resistance heating is most popularly used in zone refining of metals with low melting point, such as Cadmium [7] and Indium-Antimonide [37]. Through an induction heating, the charge can be heated up rapidly by coupling in an electromagnetic field. The induction heating devices can melt most of semiconductors or metals with high electrical conductivity. The big advantage is an inherent strong stirring in the melt actuated by electromagnetic field, which makes the induction heating zones more favorable in refining purposes, e.g. Aluminium [38], Copper [39] as well as Germanium refining [40]. For refining some refractory metals, like Chromium, Niobium, Silicon, etc., electrical discharge heating is usually preferred because of its high energy density. For examples, an electron beam furnace was used to refine Silicon [41], and hydrogen plasma arc furnace was applied in Chromium refining [42]. The Radiation heating is another heating way to achieve short zone length in zone refining. The heating structure involves a halogen lamp acting as heating resource and a mirror (consisting of ellipsoidal reflector) used to concentrate light. It can provide high power to refine materials with high melting point, such as Germanium [17] and Silicon [43]. More details about them have been laid out in Table 3.

Zone refining is generally engaged in one or more heating elements moving through the charge with a very low velocity. To attain a high purity metal, multiple numbers of passes must be performed. If only one heater is applied (single- 
Table 3. Different aspects of various heating methods in zone refining [16] [36].

\begin{tabular}{|c|c|c|c|}
\hline Heating methodology & Advantages & Disadvantages & Application \\
\hline Resistance heating & Simple, practical, cheap & $\begin{array}{l}\text { Difficult in control of zone length; } \\
\text { more risk on contamination from } \\
\text { container }\end{array}$ & $\begin{array}{l}\text { Most common heating element; } \\
\text { more suitable for small charges } \\
\text { with modest melting point } \\
\text { (less than } 500^{\circ} \mathrm{C} \text { ) }\end{array}$ \\
\hline Induction heating & $\begin{array}{l}\text { Providing higher power; Shorter } \\
\text { zone can be established; providing } \\
\text { stirring degree; less possibility of } \\
\text { contamination from container }\end{array}$ & $\begin{array}{l}\text { Occupy more floor space; expensive; } \\
\text { power probably changing sharply as } \\
\text { the variation of position, conductivity, } \\
\text { and thickness of the charge }\end{array}$ & Semiconductors and most metals \\
\hline Electrical discharge & Melt the refractory metal & Demand on vacuum system; expensive & Refractory metals \\
\hline Radiation heating & $\begin{array}{l}\text { More feasible to get short zone } \\
\text { length; less possibility of } \\
\text { contamination from container; } \\
\text { possible to melt refractory metals }\end{array}$ & $\begin{array}{l}\text { Need one pair of spherical concave } \\
\text { mirror; Occupy more floor space; } \\
\text { precise radiation path and focus }\end{array}$ & Most Metals \\
\hline
\end{tabular}

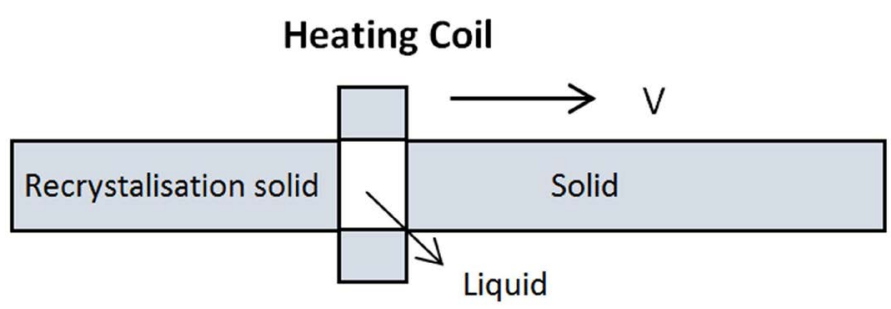

(a)

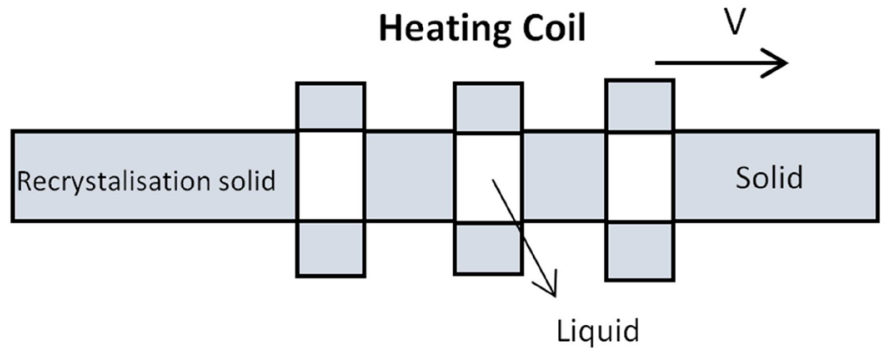

(b)

Figure 5. Sketch of single-zone refining (a) and multi-zones refining (b).

zone refining, Figure 5(a)), the heater must be repeated in many passes, leading to an extremely time consuming process. In contrast, multi-zones refining (see Figure 5(b)) could save time significantly, as applying " $\mathrm{N}$ " numbers of zones once in one pass has the same efficiency result as performing " $N$ " passes in a single-zone system. However, the inevitable mutual thermal interaction between each two adjacent zones would cause a decrease in temperature gradient along the solid, consequently increasing back diffusion of impurities (i.e. reducing refining efficiency), e.g. in the case of Tellurium [20].

\section{Possibilities to Improve Zone Refining Efficiency}

\subsection{Optimizing Experimental Parameters}

Optimization of the process parameters in a zone refining process is done with 
the aim to improve refining efficiency and to reduce the time it takes to attain ultimate concentration distribution. Generally, the main parameters to be optimized are movement velocity of heating element, zone length, and the number of passes. Zone length is not an independent factor but a consequence of power, movement velocity of heating element, type of cooling system and the thermal conductivity of charge and crucible. Lowest zone movement velocity strongly extends the whole process time and hence should be maintained to an appropriate value in balance with the refining efficiency. The optimization of zone length and the number of passes is more complicated than optimization of velocity because they can affect each other as well as they both depend on the property of treated materials.

When researching on parameters optimization of zone refining of aluminium with a constant zone length, Kino, et al [44] concluded that through adaption of zone movement velocity between $24-55 \mathrm{~mm} / \mathrm{h}$, zone length smaller than $30 \mathrm{~mm}$ (900 mm of total bar length) as well as applying 10 times of zone passes, around $80 \%$ of the Aluminum bar has been refined from $5 \mathrm{~N}$ to $6 \mathrm{~N}$. However, many researches have indicated that it is not necessary to keep the zone length constant from one pass to the next or even in the same pass. For example, Burris et al. [45] showed that a refining regime with longer zones (increased power) for the early passes, followed by shorter zones (reduced power) for the later passes, is more effective to achieve an optimum efficiency. Also, Pfann, et al [16] suggested the use of a longer zone in the first portion of the ingot, followed by a shorter zone in the second portion in one longitudinal traversing pass. That means, long zone length favors more rapid initial purification while short zone length allows much better ultimate segregation and removal [29]. That is due to the fact that longer zones have larger melt volumes, holding more rejected impurities during crystallization (for those with $\mathrm{k} \ll 1$ ). However, in the final stage of refining (after many passes) and at the same location, a larger zone has higher average impurity concentration than a smaller one. The reason can be explained due to the slope of the impurities concentration diagram along the bar. This slope is significantly bigger after many passes in comparison to that after one pass. Therefore, considering a specific part of the diagram with sharper slope, includes higher value changes in contrast to the same region in a moderate slope curve.

In multi-pass zone refining, it is well known that the best refining efficiency in the first zone pass is achieved by normal freezing, i.e. the zone length is equal to the length of the bar [46]. The optimized zone lengths in following zone passes have been investigated by different researchers mostly through numerical calculations and modelling. Rodway [29] established the variable zone size (VZS) optimization technique by performing continuous adjustment of the zone length so that the solute concentration in the liquid will become equal to that in the solid at the melting interface at all times. They proved theoretically that by using this technique; i.e. changing the zone length along the bar in each pass, the center of gravity of any given impurity (the same as impurity concentration) is moved to 
the far end of the bar, even further than any other zone molten scheme. That means through VZS technique, the production value of the final product with the same purity efficiency is considerably higher. But it is not validated experimentally due to the huge difficulty in instant adjustment of zone length. With the aim of maximizing the separation of impurities in the first half of the bar in each pass, Ho, et al [47] and Ghosh, et al [48] have conducted more practical optimization approaches, in which an optimal zone length is quantitatively evaluated in every single pass. The biggest difference between these two approaches was the dependence (in [47]) or independence (in [48]) of the optimum zone length from distribution coefficients of impurities. In contrast to the above mentioned works, Spim, et al [28] simulated a model of zone length adaption during different passes. In this model e.g. the zone length is kept equal to $0.2 \mathrm{~L}$ for the initial three passes, followed by $0.1 \mathrm{~L}$ for the subsequent four to six passes, and then $0.05 \mathrm{~L}$ for the remnant passes $(\mathrm{L}=$ the total length of the bar). This model is easier to control and its results showed to be even more satisfactory in comparison with VZS technique.

\subsection{Cropping and Connecting}

In conventional procedures of zone refining, the refining effectiveness per zone pass decreases while the number of passes increases until the impurities cannot be removed any more. In this case the ultimate impurity concentration distribution profile is achieved (as shown in Figure 3). However, by applying cropping (means cutting) the impurity-enriched regions at the beginning or the end of the rod after each pass or each group of passes and then connecting the impurityreduced regions to a new bar for next zone passes (as seen in Figure 6), this phenomenon will be extensively alleviated. It means, under this procedure the refining effectiveness per zone pass decreases only up to a certain number of passes followed by a constant phase, and the final purity is much higher than that from the conventional procedure [49]. It is a common way to achieve $6 \mathrm{~N}$ Silicon [41], 7N Tellurium [7] or 7N Aluminium [22]. The influence of cropping procedure on purification in comparison to the conventional methods is illustrated in Figure 7, taking $\mathrm{Al}$ as an example [22].

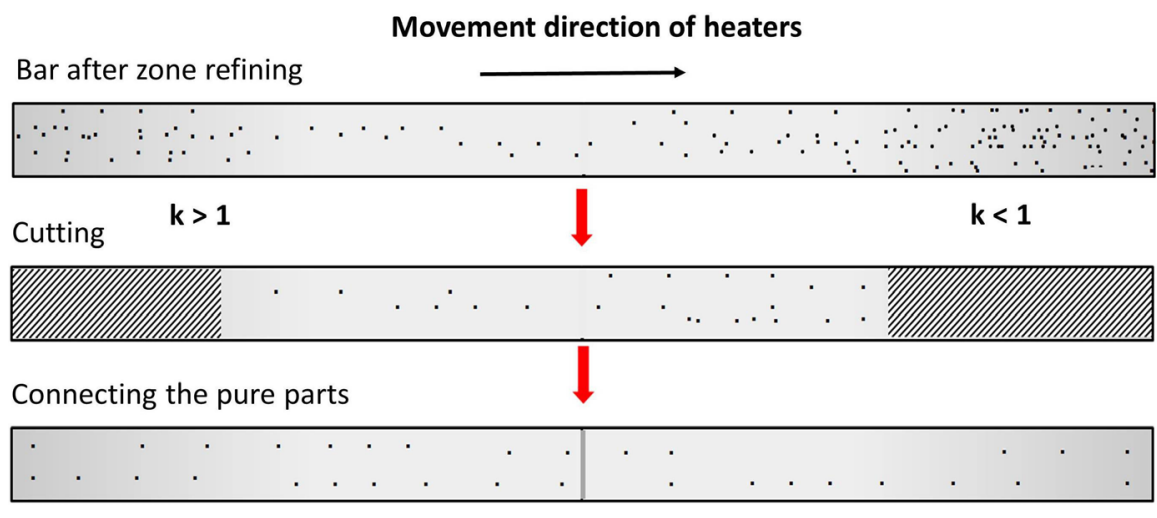

Figure 6. Sketch of cropping and connecting process. 


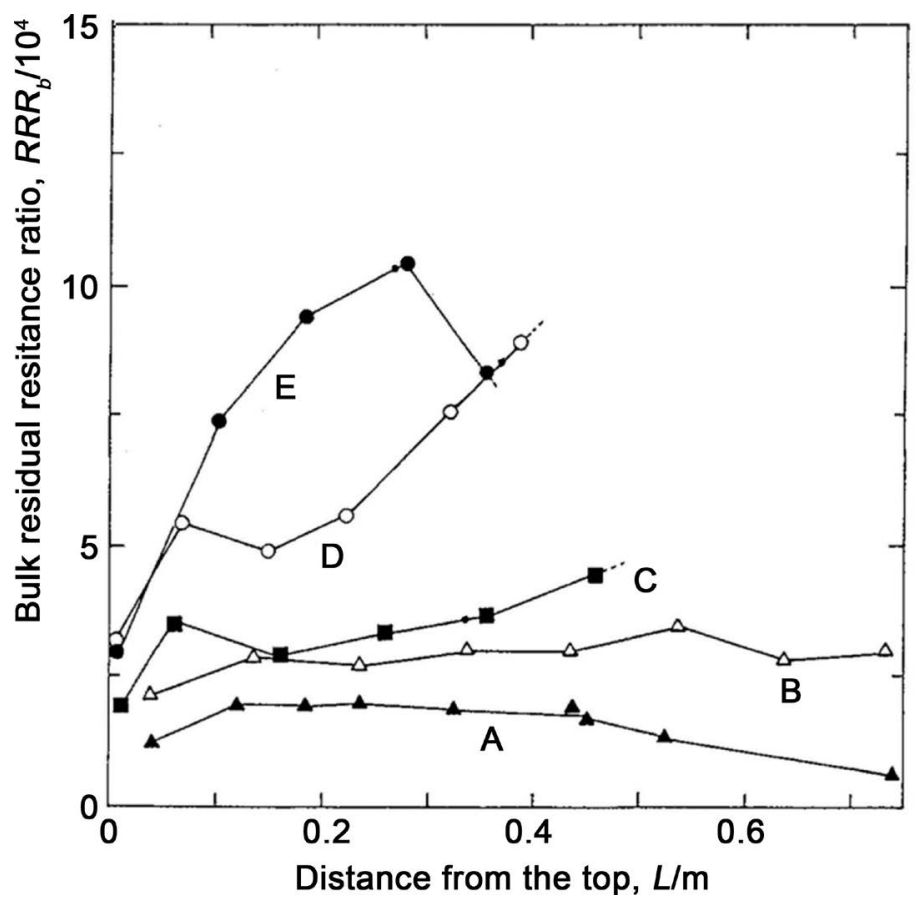

Figure 7. Bulk residual resistance ratio RRR plotted as a function of distance from the top in the last zone pass of aluminum bars A, B, C, D and E, where bar A: 1 pass and bar B: 10 passes, both without cropping; bar C: 5 passes without and subsequently 5 passes with cropping; bar D: 30 passes and E: 60 passes, both using cropping [22].

In addition, most of zone refining theories, such as Pfann equations (Equation (4) and (5)) make the assumption that the impurity diffusion in the solid is negligible. This assumption is though only allowed if high-quality crystals are grown. In reality, the crystal quality of substance produced by zone refining is often very poor, with the result that the impurities have less activation energy, leading to higher diffusivity [25]. Higher diffusivity (i.e. $\mathrm{D}>10^{-10} \mathrm{~m}^{2} / \mathrm{sec}$ at the melting point [49]) can cause backward diffusion to the already frozen pure area. In this case, the usage of the cropping procedure will be even more necessary, e.g. to remove $\mathrm{Sc}$ in the refinement of $6 \mathrm{~N}-\mathrm{Al}$ with the aim to reach $7 \mathrm{~N}$ [22].

\subsection{Inclination of the Charge}

It is a popular phenomenon that the shape of the bar becomes wedged when it was refined in an opened horizontal boat [50]. The taper is maybe still very slight after one zone pass, but it can become more significant after more passes, even result in an overflow of the melt at the end of the boat. This bulk transport is attributed to the changes of density while melting, although the effects of surface tension and wetting between liquid and crucible play an extensive role on that as well [36]. When the molten state density is less than that of solid, the bulk is transported in the reverse direction to the molten zone movement, resulting in an increased mass of the bulk at the beginning of the bar (see Aluminum example in Figure 8(a)). In contrast, the bulk is transported in the same direction as the zone movement, for the case that the molten state density is bigger than that 
of solid (e.g. Germanium in Figure 8(b)). As bulk tapering is an unwanted phenomenon, it is tried to be largely eliminated by locating the crucible with an inclination angle, as defined in Equation (9)) [16]:

$$
\theta_{c}=\arctan \left(\frac{2 h_{0}(1-\alpha)}{l}\right)
$$

where, $h_{0}$ is the initial height of the bar, $\alpha$ is the ratio of density in solid state to that of liquid and $l$ is the zone length. It has been numerically demonstrated that the zone refining process is not affected by this modest inclination of the bar from the heat transfer point of view [37].

\subsection{Application of an Electric Current for Impurity Transport}

In order to reduce the impurities with a distribution coefficient close to unity (which are difficult to be removed via common ways), an electric current field is helpful to be applied as an additional heating concept during zone refining (see Figure 9). That is done with the intension that the electromigration improves the segregation of impurities at the boundary interface. However, this mechanism can only work well in metallic systems with quite high electric conductivity (as an example Selenium removal from Cadmium [52]).

\section{Numerical Modeling}

As mentioned above, the known optimization regimes for experimental parameters are of limited general use, as they are strongly dependent on individual

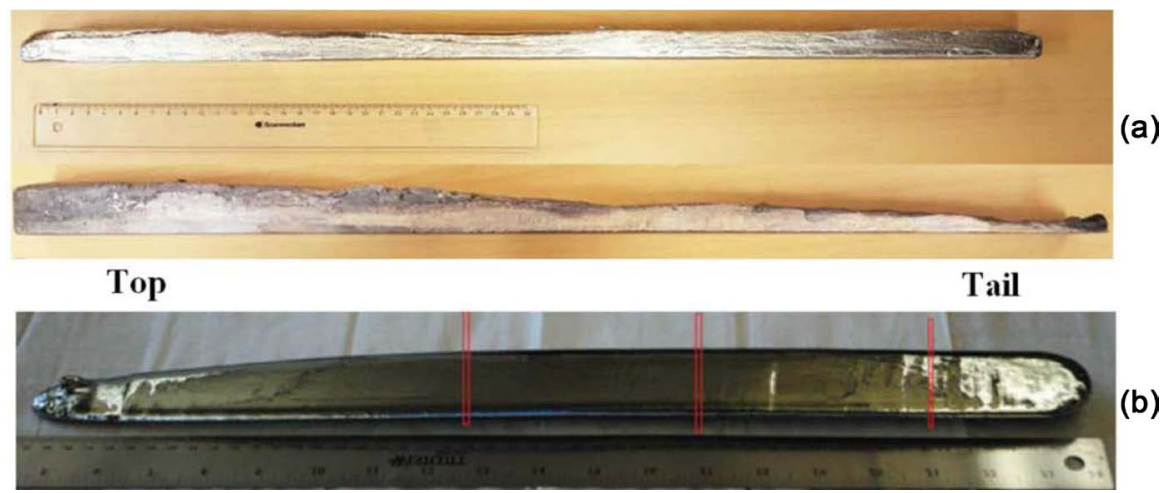

Figure 8. Bulk transport phenomenon: (a) Aluminium and (b) Germanium [51] [18].

Moving direction of heaters

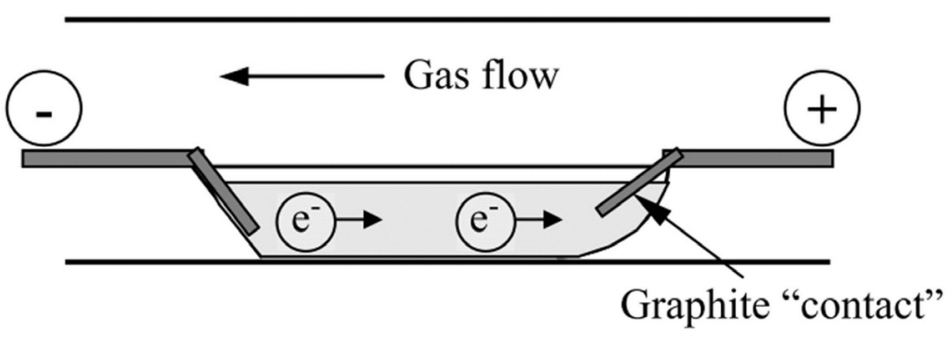

Figure 9. Scheme of a set-up and application of an electric current [52]. 
system characteristics. Consequently, numerous numerical models have been developed to predict the solute distribution or to optimize experimental parameters as well as to give guidance for empirical trials.

For single pass zone refining, the impurity distribution profile after one pass refinement can be predicted with Equations ((4) and (5)). Regarding to handling the multi-pass zone refining, a basic differential equation, derived independently by Lord [53] and Reiss [54], was introduced to build the numerical model. The differential equation relates the mass balance in the molten zone, e.g. the change of melt concentration in this region results from the difference between the fluxes of solute entering and leaving the zone. It is given by:

$$
\frac{Z}{k} \mathrm{~d} C_{S_{(X)}}^{n}=\left(C_{S_{(X+Z)}-1}^{n-1}-C_{S_{(X)}}^{n}\right) \mathrm{d} x \text { for } 0 \leq X \leq 1-Z
$$

and

$$
\mathrm{d} C_{S_{(X)}}^{n}=\frac{1-k}{L-X} C_{S_{(X)}}^{n} \mathrm{~d} x \text { for } 1-Z \leq X \leq 1
$$

Lord and Reiss have derived an exact expression of the impurity concentration distribution as a function of distance $X$ respectively. However the Lord model is valid only with the assumption of semi-infinite ingots and the Reiss model is accurate only for $\mathrm{k}$ in the range of 0.9 to 1.1, which confines the application of them. Therefore some new models are put forward-as explained briefly in the following-to provide a more accurate simulation of global impurity concentration distribution profile.

\subsection{Iterative Modeling with Constant $k$}

Based on the typical assumptions and equations stated in section 2 and the above differential Equations ((10), (11)), Spim, et al [28] proposed a new iterative model, concentrated on simulating distribution activity of impurity elements at any stage for multi-pass zone refining process. In this model, the solute concentration profiles for each pass of a molten zone have been quantified by considering four different regions along the sample: Region 1, surface $(X=0)$; Region 2, intermediate $(0<X \leq 1-Z)$; Region 3, normal freezing $(1-Z<X<1)$; and Region 4, end of the sample $(X=1)$. This simulation model can be used to research on the effects of zone length and distribution coefficient $\mathrm{k}$ on the refining efficiency, including the ultimate impurity concentration distribution as well as the minimum zone passes necessitated to reach the final state. It has proved in [28] that a combination of initial long zones followed by shorter ones can improve the refining efficiency (shown in Figure 10(a)), which is even better than applying a continuous variation of zone size (as shown in Figure 10(b)).

\subsection{Iterative Modeling with Variable $k$}

Generally speaking, the equilibrium distribution coefficients are calculated from the solute concentrations of liquid and solid phases at a particular temperature (e.g. eutectic temperature) in the equilibrium diagram, and are used for simulation 


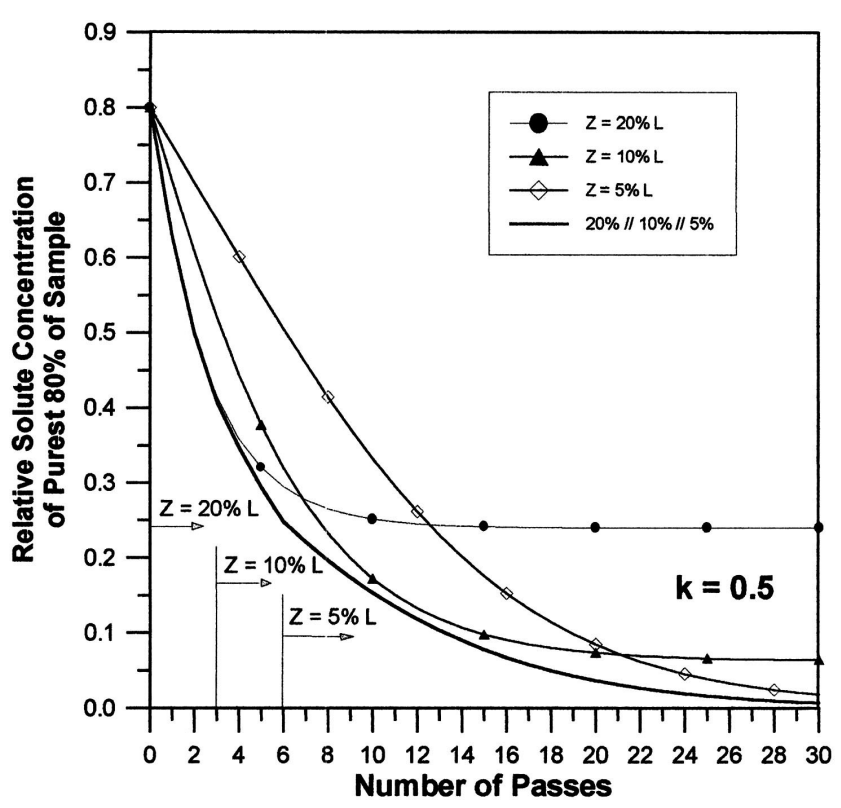

(a)

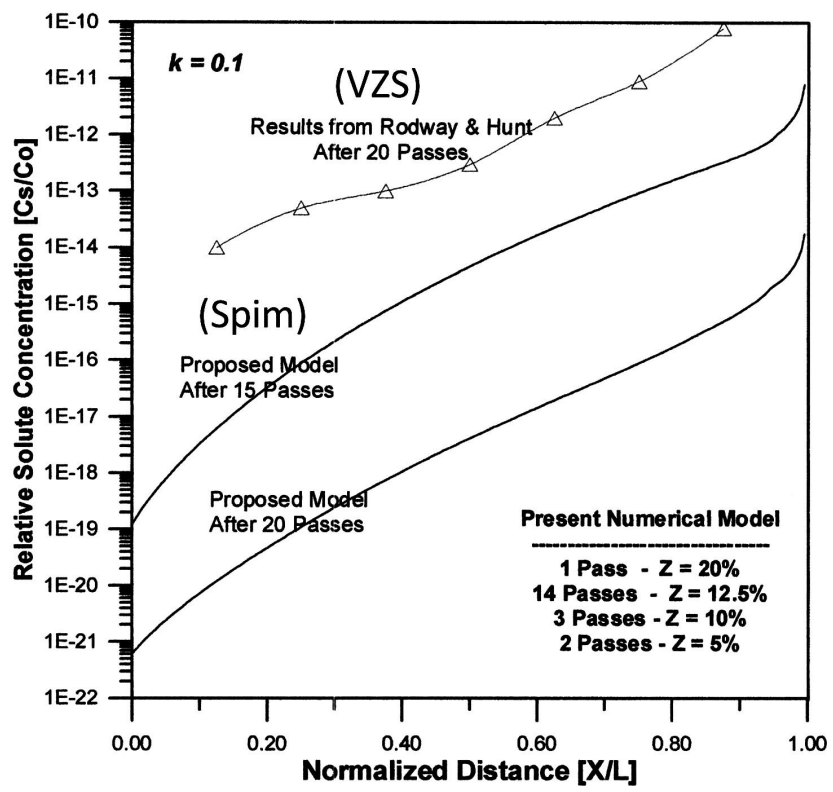

(b)

Figure 10. (a) Computed mean composition of the purest $80 \%$ of the sample $(0<Z<0.8)$ as a function of the number of passes and zone length with application of Spim model; (b) comparison of zone length optimization methods between Spim and VZS model [28].

purposes as a constant value along the whole zone refining process, as seen in chapter 5.1. However, using the same simulation model, Cheung, et al. [30] researched on the effects of variable $k$ instead of constant $k$ on the efficiency of simulations with a combination of theoretical and experimental analysis. The variable $k$ is attained from a phase diagram database containing the variation of liquidus and solidus line slopes built according to the corresponding phase diagram, as shown in Figure 11(a). Each individual $C_{L}$ refers to a corresponding $C_{S}$ and resulting in a specific $k$. Therefore during simulation processing, for each $C_{L}$ at any melting zone, the $k$ could readily be accessed from the database to provide more accurate input values of $k$ for the model simulation (see in Figure 11(b)). Comparing the two model simulations with constant-and variable $k$ for aluminium refinement, it can be concluded that using variable $k$ in the simulation is much closer to the experimental impurity distribution profiles than the taking a constant $k$ into account. The concentration profiles after refinement predicted by them differ from each other by two orders of magnitude in zone refining of $\mathrm{Al}$ with eight zone passes, and the efficiency of purification is strongly underestimated when a constant value for $k$ is considered in simulations, which can be easily seen in Figure 11(c) [30].

\subsection{Iterative Modeling Considering Diffusion Region}

A new numerical simulation model has been proposed by Nakamura, et al [23] on the basis of the Equations ((10) and (11)). The model treats the molten zone with two individual regions, i.e. diffusion and stirring region, as presented in Figure 12(a). Their model introduces a transfer ratio (q) for the amount of solute 

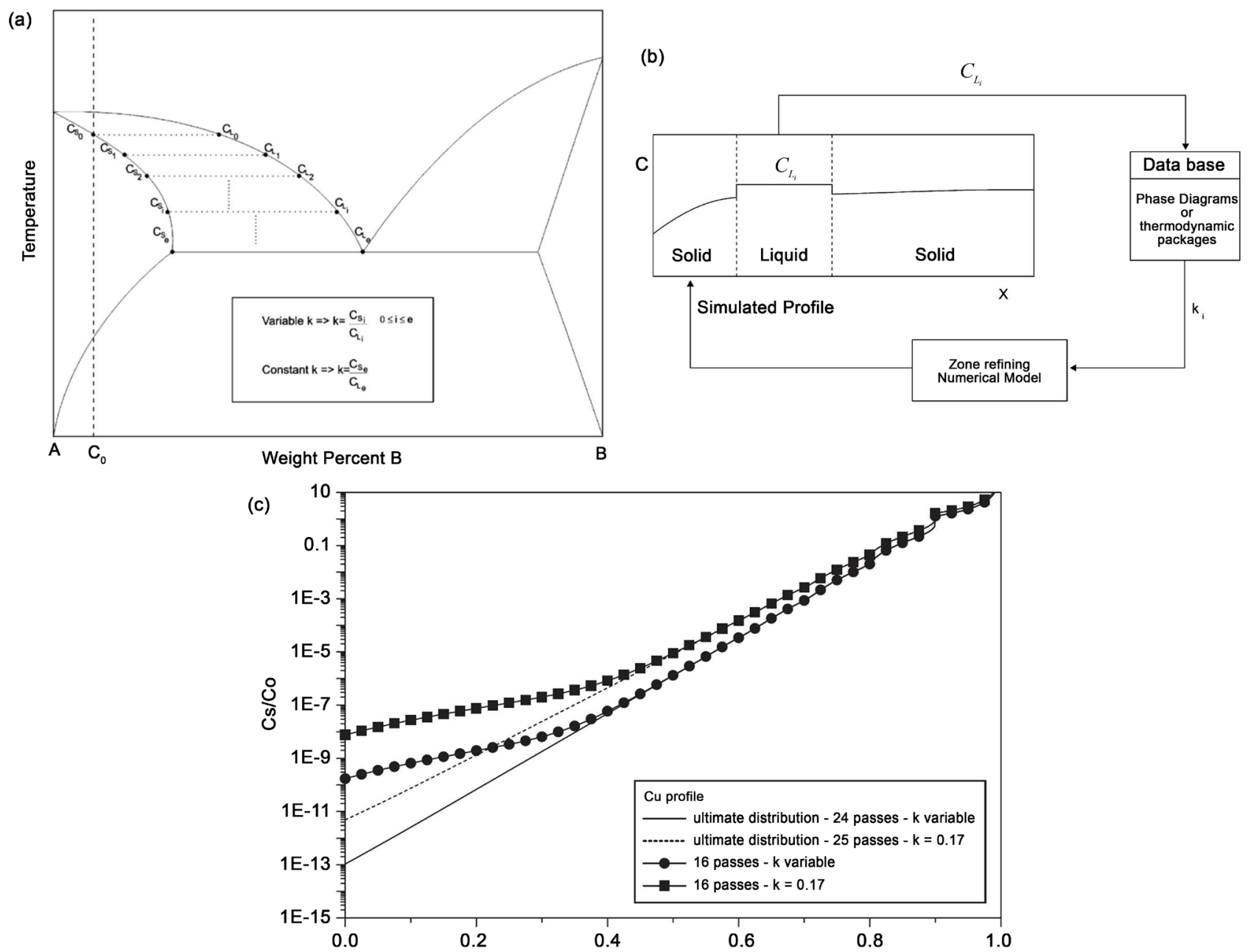

Figure 11. Schematic representation of calculation of variable $k(a)$ and the application flowchart of the variable $k$ numerical program (b), and comparison between numerical simulation with the application of constant $k$ and variable $k$ (c) [30].

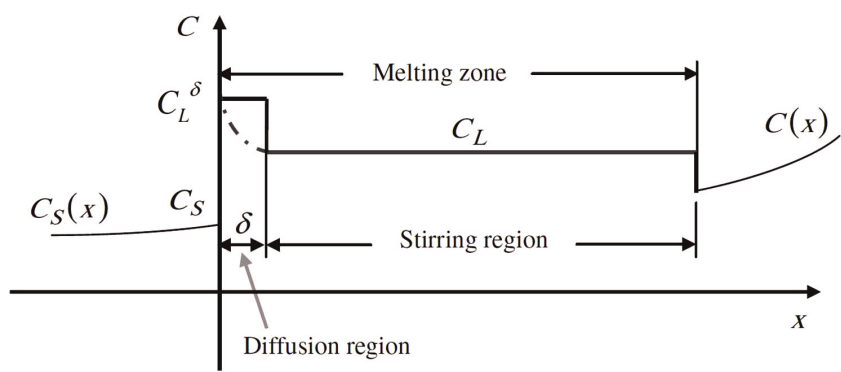

(a)

\begin{tabular}{|c|c|c|c|c|c|c|c|}
\hline & \multicolumn{6}{|c|}{ Melting zone } & \\
\hline \multirow{2}{*}{$\begin{array}{l}\text { Region } \\
\text { Segment }\end{array}$} & $\begin{array}{l}\text { Diffusion } \\
\text { region }\end{array}$ & \multicolumn{5}{|c|}{ Stirring region } & \\
\hline & 1 & 2 & 3 & 4 & $\cdots$ & $m$ & \\
\hline \multirow{4}{*}{$\begin{array}{r}\text { Composition } \\
(i)\end{array}$} & $n(1-q)$ & \multicolumn{5}{|c|}{$n q$} & \\
\hline & $C_{\mathrm{L}(i-1)}$ & $C_{\mathrm{L}(i-1)}$ & $C_{\mathrm{L}(i-1)}$ & $C_{\mathrm{L}(i-1)}$ & $\ldots$ & $C_{\mathrm{L}(x)}$ & $C_{(x)}$ \\
\hline & \multicolumn{7}{|c|}{5} \\
\hline & $C_{\mathrm{L}}^{\delta}{ }_{(i)}$ & $C_{\mathrm{L}(i)}$ & $C_{\mathrm{L}(i)}$ & $C_{\mathrm{L}(i)}$ & $\cdots$ & $C_{\mathrm{L}(i)}$ & $C_{(x)}$ \\
\hline
\end{tabular}

(b)

Figure 12. Schematic diagram of molten zone (a) and computation model considering diffusion region (b) [23].

emitted from diffusion region to that dissolves into the stirring region during solidification (as seen in Figure 12(b)). On the other hand and when researching on distribution of solute in crystal growth, J. A. Burton, et al [55] developed two important equations, which are Equation (1) as well as Equation (12):

$$
\frac{C_{L}-C_{S}}{C_{L}^{\delta}-C_{S}}=\exp (-R \delta / D)
$$


From the definition of transfer ratio $q$, it is known that the exponential factor in the two above equations is identical to the transfer ratio $q$,

$$
\exp (-R \delta / D)=q
$$

In this equation, $\delta$ and $q$ can be calculated when each one is explicit, as the $R$ and $D$ are already determined for a specific refining event. Therefore before using this model, $\delta$ and $q$ must be estimated by comparison the results of experiment with the results of simulation with setting of different $\delta$ and $q$ for one impurity. The advantage of this model is that when $\delta$ is determined by parametric fitting for one impurity, the distribution profile of other impurities can be derived by using the same value of $\delta$.

\subsection{Assessment of Modelling versus Experiment}

As a large variety of experimental parameter combinations (presented in section 2) exist during the course of optimizing the zone refining process and improving the refining efficiency, investigation through experiments alone is very timeconsuming and is even not practicable. Besides, the optimum experimental parameters differ from individual zone refining systems. Therefore, the application of numerical model as stated above is a good assistant to guide the experiment performance. That can predict the influence of each parameter on the refining results and get the theoretical optimum parameters combination with short time and low cost. In some cases, to get a clear insight in the variation of zone length, zone temperature distribution, zone shape, etc., the overall heat transfer in the system should be simulated as well [17] [21] [38]. However, many assumptions should be taken in the development of simulation, such as neglecting diffusion of impurities in the solid, assuming complete planar solidification interface, assuming homogeneous concentration distribution in the molten zone, not considering the interaction activity among different impurities, assuming consistent stability of growing rate, etc. All of these assumptions inevitably result in the deviation of the simulation results from reality. Hence, the experiment research is indispensable to prove the trueness of the simulation prediction or to correct the model itself. As a result, it is always suggested to combine both simulation and experiment to conduct the research on zone refining of metals.

\section{High Purity Analysis Methods}

After accomplishment a high purity metal refining through zone melting, a challenging task is to analyze the impurity concentration in the product. Currently a variety of available methodologies are existed to fulfill this task, each based on different mechanism with individual detection limit and accuracy.

\section{- Residual resistivity ratio (RRR)}

According to the Matthiessen's rule $\rho=\rho_{i}(T)+\rho_{0}$, the electrical resistivity of metals contains the ideal resistivity $\rho_{i}(T)$, a temperature-dependent function of lattices vibrations as well as $\rho_{0}$, the temperature-independent sum of all kinds of lattice defects. Impurity elements occupy the lattice or are located in the lat- 
tice as interstitial atoms, resulting in the appearance of defects, such as dislocation, stacking faults, etc. [56]. These defects will increase the residual resistivity $\rho_{0}$ when temperature decreases nearly $0 \mathrm{~K}$ especially. Based on this, residual resistivity ratio $(R R R=(R(300 K)) /(R(4 K))$ is used to measure the qualitative level of purity of metals [22] [23] [56]. A higher value of RRR represents higher purity, such as value of 30.000 in the bulk aluminum standing for purity of $6 \mathrm{~N}$ and 90.000 corresponding to purity of $7 \mathrm{~N}$. But the result from this method is only indicating the total purity of the metal, without giving any quantitative or qualitative indication about the type and concentration of individual impurities.

\section{- Glow-discharge mass spectrometry (GDMS)}

GDMS is a versatile and important tool to analyze the trace elements with remarkable high sensitivity. Its principle is to measure the ion beam intensity, i.e. the numbers of ions arriving at detector after ionization of the material with plasma, which is proportional to the number of the elements in the sample. Its sensitivity could be up to $1 \mathrm{ppb}$ for most of the elements, and up to $1 \mathrm{ppm}$ for the light and non-metallic elements, such as Carbon, Nitrogen, Oxygen [57].

- Inductively coupled plasma-mass spectrometry/optical emission spectrometry (ICP-MS/ICP-OES)

ICP-MS and ICP-OES can also be used to determine the compositions of different materials with very low detection limit. They both use the inductively coupled plasma as the ion source, while differs from each other in the type of detecting signals. The sample system between ICP-MS and ICP-OES is similar, but the detection limit of ICP-OES is typically $100-1000$ times poorer than that of ICP-MS, with most elements in the range of $1-10 \mathrm{ppb}$ [58]. The application field and detection limit are similar between GDMS and ICP-MS; however, ICP-MS has the advantage of lower disturbance from interfering molecules and shorter analytical time, while GDMS excels in lower detection limits [59].

In addition, there are also some other analytical methodologies, such as Atomic absorption spectrometry with graphite furnace (AASGF) with the limit of detection limit range between $10-400 \mathrm{ppb}$ [20], Spark source mass spectrometry (SSMS) with detection limit of sub ppm [60], X-ray fluorescence (XRF) with detection limit of $0.001 \%$ [61], and van der Pauw Hall effect measurement [18] [62]. The detailed comparison of these high purity analysis methods has been presented in Table 4 .

\section{Research Vision}

Zone refining is a validated and effective process to produce high purity metals. The parametric optimization and numerical models for zone refining of various materials aiming to improve the refining efficiency have been researched extensively in the last decades. However, the efficiency and the yield have always been the issues of zone refining. Therefore, further researches on zone refining of metals could be done with the center of following aspects: first, using current simulation model to optimize the experimental parameters for any given system 
Table 4. Comparison of various high purity analysis methods [58] [63] [64] [65].

\begin{tabular}{ccccccc}
\hline & Detection limit & Precision & Quant-analysis & Sample phase & Operating cost & Capital cost \\
\hline RRR & N.A. & N.A. & No & Solid & Medium & Medium/low \\
GDMS & Excellent for most elemetns & High & Yes & Solid & High & Very high \\
ICP-MS & Excellent for most elments & $1 \%-3 \%$ & Yes & Solution & High & Very high \\
ICP-OES & Very good for most elements & $0.3 \%-1 \%$ & Yes & Solution & High & High \\
AASGF & Excellent for some elements & $1 \%-5 \%$ & Yes & Solid/Solution & Medium & Medium/high \\
SSMS & Good & $3 \%-7 \%$ & Yes & Solid & Medium/low & Medium/low \\
XRF & Good & High & Yes & Solid & Medium/low & Very high \\
Van der Pauw Hall effect & N.A. & N.A. & No & Solid & Low & Low \\
\hline
\end{tabular}

as a guidance for experiments, meanwhile reversely applying experimental results to further correction of the numerical model; second, upgrading the common zone refining equipment, such as using multi-zones scheme, installation of external temperature detectors for a better control of the molten zone length, improving the automatization, etc. is also a good view to meet the target; third, focusing on some individual details, such as the variation of molten zone shape (changed by power, velocity, physical properties of the material), effects of temperature gradient on refinement, the interaction activity of different impurities, etc.; fourth, comparison research on zone refining potential or efficiency of different metals, or comparison/cooperation research on zone refining with other refining methodologies, such as cooled finger crystallization [68] [69], vacuum distillation [68] [69] [70] [71] [72], etc.

\section{Acknowledgements}

The Authors would like to thank the China Scholarship Council (CSC) for the financial support of the scholarship holder X. Zhang.

\section{References}

[1] Hinrichs, J. (2014) High Purity Aluminium Analysis. Aluminum International Today - Analysis \& Testing, 4-5.

[2] Ghosh, K., Mani, V.N. and Dhar, S. (2009) Numerical Study and Experimental Investigation of Zone Refining in Ultra-High Purification of Gallium and Its Use in the Growth of GaAs Epitaxial Layers. Journal of Crystal Growth, 311, 1521-1528. https://doi.org/10.1016/j.jcrysgro.2009.01.102

[3] Sangsingkeow, P., Berry, K.D., Dumas, E.J., Raudorf, T.W. and Underwood, T.A. (2003) Advances in Germanium Detector Technology. Nuclear Instruments and Methods in Physics Research Section A: Accelerators, Spectrometers, Detectors and Associated Equipment, 505, 183-186. https://doi.org/10.1016/S0168-9002(03)01047-7

[4] Butterman, B.W.C. and Jorgenson, J.D. (2005) Germanium. US Geological Survey, Reston, Virginia.

[5] Singh, A.J., Mathur, B.S. and Suryanarayana, P. (1975) Preparation of Electronics 
Grade Bismuth, Antimony, Tellurium, Cadmium and Zinc by Vacuum Distillation and Zone Refining.

[6] Zaiour, A., Zahraman, K., Roumie, M., Charara, J., Fawaz, A., Lmai, F. and Hage-Ali, M. (2006) Purification of Tellurium to Nearly 7N Purity. Materials Science and Engineering B: Solid-State Materials for Advanced Technolog, 131, 54-61.

[7] Munirathnam, N.R., Prasad, D.S., Sudheer, C.H., Rao, J.V. and Prakash, T.L. (2005) Zone Refining of Cadmium and Related Characterization. Bulletin of Materials Science, 28, 209-212. https://doi.org/10.1007/BF02711249

[8] Su, C.-H. and Sha, Y.-G. (1998) Segregation Coefficients of Impurities in Selenium by Zone Refining. Journal of Crystal Growth, 187, 569-572.

https://doi.org/10.1016/S0022-0248(98)00037-2

[9] Curtolo, D.C., Friedrich, S. and Friedrich, B. (2017) High Purity Germanium, a Review on Principle Theories and Technical Production Methodologies. Journal of Crystallization Process and Technology, 7, 65-84.

https://doi.org/10.4236/jcpt.2017.74005

[10] Scott Hubbard, G., Haller, E.E. and Hansen, W.L. (1975) Characterization of Polycrystalline Zone-Refined Ingots of High-Purity Germanium. Nuclear Instruments and Methods, 130, 481-485. https://doi.org/10.1016/0029-554X(75)90046-4

[11] Cressel, L.G. and Powell, J.A. (1957) John Wiley \& Sons, Inc., New York.

[12] Pfann, W.G. and Olsen, K.M. (1955) Bell Laboratories Record, 33, 201.

[13] Vegad, M. and Bhatt, N.M. (2014) Review of Some Aspects of Single Crystal Growth Using Czochralski Crystal Growth Technique. Procedia Technology, 14, 438-446. https://doi.org/10.1016/j.protcy.2014.08.056

[14] Scheel, H.J. (2003) The Development of Crystal Growth Technology. John Wiley \& Sons, Inc., New York, 3-14. https://doi.org/10.1002/0470871687

[15] Pfann, W.G. (1952) Principles of Zone Melting. The Journal of the Minerals, Metals \& Materials Society (TMS), 4, 747-753. https://doi.org/10.1007/BF03398137

[16] Pfann, W.G. (1966) Zone Melting. 2nd Edition, John Wiley \& Sons, Inc., New York.

[17] Wang, S., Fang, H.S., Jin, Z.L., Zhao, C.J. and Zheng, L.L. (2014) Integrated Analysis and Design Optimization of Germanium Purification Process Using Zone-Refining Technique. Journal of Crystal Growth, 408, 42-48. https://doi.org/10.1016/j.jcrysgro.2014.09.019

[18] Yang, G., Govani, J., Mei, H., Guan, Y., Wang, G., Huang, M. and Mei, D. (2014) Investigation of Influential Factors on the Purification of Zone-Refined Germanium Ingot. Crystal Research and Technology, 49, 269-275. https://doi.org/10.1002/crat.201300418

[19] Shim, M., Kim, Y.M., Lee, H.H., Hong, S.J. and Lee, J.H. (2016) Separation Behavior of Impurities and Selenium Reduction by the Reactive Zone Refining Process Using High-Frequency Induction Heating to Purify Te. Journal of Crystal Growth, 455, 6-12. https://doi.org/10.1016/j.jcrysgro.2016.09.032

[20] Roumie, M., Zahraman, K., Zaiour, A., Mohanna, Y. and Hage-Ali, M. (2006) Study of Segregation Process of Impurities in Molten Tellurium after One Pass of Three Conjoint Zones in Zone Refining. Journal of Crystal Growth, 289, 260-268. https://doi.org/10.1016/j.jcrysgro.2005.11.002

[21] Liu, Y.C., Moss, R. and Dost, S. (2006) A Computational Thermal Analysis for the Zone-Refining Processes of Cd and Te. Journal of Crystal Growth, 293, 146-156. 
https://doi.org/10.1016/j.jcrysgro.2006.04.109

[22] Hashimoto, E. and Ueda, Y. (1994) Zone Refining of High-Purity Aluminum. Materials Transactions, 35, 262-265.

[23] Nakamura, M., Watanabe, M., Tanaka, K., Kirihata, A., Sumomogi, T., Hoshikawa, H. and Tanaka, I. (2014) Zone Refining of Aluminum and Its Simulation. Materials Transactions, 55, 664-670.

[24] Shah, J.S. (1974) Crystal Growth. Pergamon Press, Oxford.

[25] Kurz, W. and Fisher, D. (1989) Fundamental of Solidification. 2nd Edition, Trans Tech Publications, Switzerland.

[26] Yao, X., Furuya, K., Nakamura, Y., Wen, J., Endoh, A. and Shiohara, Y. (2017) NdBCO Melting and Solidification by a Zone-Melting Method. Journal of Materials Research, 10, 3003-3008. https://doi.org/10.1557/JMR.1995.3003

[27] Scheil, E. (1947) Metallforschung. 2, 69.

[28] Spim, J.A., Bernadou, M.J.S. and Garcia, A. (2000) Numerical Modeling and Optimization of Zone Refining. Journal of Alloys and Compounds, 298, 299-305. https://doi.org/10.1016/S0925-8388(99)00655-6

[29] Rodway, G.H. and Hunt, J.D. (1989) Optimizing Zone Refining. Journal of Crystal Growth, 97, 680-688. https://doi.org/10.1016/0022-0248(89)90571-X

[30] Cheung, N., Bertazzoli, R. and Garcia, A. (2008) Experimental Impurity Segregation and Numerical Analysis Based on Variable Solute Distribution Coefficients during Multi-Pass Zone Refining of Aluminum. Journal of Crystal Growth, 310, 12741280. https://doi.org/10.1016/j.jcrysgro.2008.01.007

[31] Pfann, B.W.G. and Labora, B.T. (1957) Zone Melting. Metallurgical Reviews, 2, 29-76.

[32] Rozin, K.M., Vigdorovich, V.N. and Krestovnikov, A.N. (1961) The Continuous Zone-Refining Method. Metall. i Topl., 5, 56-73.

[33] Kennedy, J.K. (1964) Continuous Zone-Refining Apparatus. Review of Scientific Instruments, 35, 25-28. https://doi.org/10.1063/1.1718702

[34] Ikeda, T., Marolf, N.J. and Snyder, G.J. (2011) Zone Leveling Crystal Growth of Thermoelectric PbTe Alloys With $\mathrm{Sb}_{2} \mathrm{Te}_{3}$ Widmanstätten Precipitates. Crystal Growth \& Design, 11, 4183-4189. https://doi.org/10.1021/cg2007588

[35] Semiconductors-Materials Processing. Http://people.seas.harvard.edu/ jones/es154/lectures/lecture_2/materials/materials. $\underline{\mathrm{html}}$

[36] Schlidknecht, H. (1964) Zonenschmelzen. Verlag Chemie, Weinheim.

[37] Roussopoulos, G.S. and Rubini, P.A. (2004) A Thermal Analysis of the Horizontal Zone Refining of Indium Antimonide. Journal of Crystal Growth, 271, 333-340. https://doi.org/10.1016/j.jcrysgro.2004.07.058

[38] Hashimoto, E., Ueda, Y., Kino, T., Hashimoto, E., Ueda, Y., Purification, T.K., Purity, U. and Journal, A. (1995) Purification of Ultra-High Purity Aluminum. Journal de Physique IV France, 5, 153-157.

[39] Zhu, Y., Mimura, K., Ishikawa, Y. and Isshiki, M. (2002) Effect of Floating Zone Refining under Reduced Hydrogen Pressure on Copper Purification. Materials Transactions, 43, 2802-2807.

[40] Wang, G., Sun, Y., Yang, G., Xiang, W., Guan, Y., Mei, D., Keller, C. and Chan, Y.-D. (2012) Development of Large Size High-Purity Germanium Crystal Growth. Journal of Crystal Growth, 352, 27-30. 
https://doi.org/10.1016/j.jcrysgro.2012.01.018

[41] Mei, P.R., Moreira, S.P., Cardoso, E., Côrtes, A.D.S. and Marques, F.C. (2012) Purification of Metallurgical Silicon by Horizontal Zone Melting. Solar Energy Materials and Solar Cells, 98, 233-239. https://doi.org/10.1016/j.solmat.2011.11.014

[42] Mimura, K., Komukai, T. and Isshiki, M. (2005) Purification of Chromium by Hydrogen Plasma-Arc Zone Melting. Materials Science and Engineering. A, 403, 11-16. https://doi.org/10.1016/j.msea.2005.03.113

[43] Reber, S., Zimmermann, W. and Kieliba, T. (2001) Zone Melting Recrystallization of Silicon Films for Crystalline Silicon Thin-Film Solar Cells. Solar Energy Materials and Solar Cells, 65, 409-416. https://doi.org/10.1016/S0927-0248(00)00120-3

[44] Kino, T., Kamigaki, N., Yamasaki, H., Kawai, J., Deguchi, Y. and Nakamichi, I. (1976) Zone Refining in Aluminum. Transactions of the Japan Institute of Metals, 17, 645-648.

[45] Burris, L., Stockman, C.H. and Dillon, I.G. (1955) Contribution to Mathematics of Zone Melting. The Journal of The Minerals, Metals \& Materials Society (TMS), 7, 1017-1023.

[46] Davis, L.W. (1959) The Efficiency of Zone-Refining Process. Transactions of the American Institute of Mechanical Engineers, 215, 672-675.

[47] Ho, C., Yeh, H. and Yeh, T. (1998) Numerical Analysis on Optimal Zone Lengths for Each Pass in Multipass Zone-Refining Processes. The Canadian Journal of Chemical Engineering, 76, 3-9.

[48] Ghosh, K., Mani, V.N. and Dhar, S. (2008) A Modeling Approach for the Purification of Group III Metals ( $\mathrm{Ga}$ and In) by Zone Refining. Journal of Applied Physics, 104, 024904. https://doi.org/10.1063/1.2959832

[49] Fischer, D. (1973) A Study on Zone Refining: Solid-Phase Impurity Diffusion and the Influence of Separating the Impure End. Journal of Applied Physics, 44, 1977-1982. https://doi.org/10.1063/1.1662502

[50] Pfann, W.G. (1953) Change in Ingot Shape During Zone Melting. The Journal of The Minerals, Metals \& Materials Society (TMS), 5, 1441-1442.

[51] Zhang, X., Friedrich, S. and Friedrich, H.C.B. (2017) Investigation of Influencing Parameters on Zone Melting Refining of Aluminium, Part One Impurities: Iron and Silicon. Proceedings of EMC 2017, 1, 327-334.

[52] Dost, S., Liu, Y.C., Haas, J., Roszmann, J., Grenier, S. and Audet, N. (2007) Effect of Applied Electric Current on Impurity Transport in Zone Refining. Journal of Crystal Growth, 307, 211-218. https://doi.org/10.1016/j.jcrysgro.2007.06.008

[53] Lord, N.W. (1953) Journal of Metals, 197, 1531.

[54] Reiss, H. (1954) Mathematical Methods for Zone-Melting Processes. The Journal of The Minerals, Metals \& Materials Society (TMS), 6, 1053-1959.

[55] Burton, J.A., Prim, R.C. and Slichter, W.P. (1953) The Distribution of Solute in Crystals Grown from the Melt. Part I. Theoretical. The Journal of Chemical Physics, 21, 1987. https://doi.org/10.1063/1.1698728

[56] Kino, T., Endo, T. and Kawata, S. (1974) Deviations from Matthiessen's Rule of the Electrical Resistivity of Dislocations in Aluminum. Journal of the Physical Society of Japan, 36, 698-705. https://doi.org/10.1143/JPSJ.36.698

[57] Guidoboni, R.J. and Leipziger, F.D. (1988) Glow Discharge Mass Spectrometry-The Newest Tool for High Purity Materials Analysis. Journal of Crystal Growth, 89, 16-20. https://doi.org/10.1016/0022-0248(88)90066-8 
[58] Tyler, G. (2001) ICP-OES, ICP-MS and AAS Techniques Compared. ICP Optical Emission Spectroscopy, 3, 1-11.

[59] Jakubowski, N., Feldmann, I. and Stuewer, D. (1995) Comparison of ICP-MS with Spark Ablation and GDMS for Direct Element Analysis of Conductive Solids. Elsevier, Amsterdam.

[60] Ure, A.M. (1982) Comprehensive Quantitative Analysis by Spark Source Mass Spectrometry: A Technique on the Brink. TrAC Trends in Analytical Chemistry, 1, 314-317. https://doi.org/10.1016/0165-9936(82)87027-1

[61] Zong, L., Zhu, B., Lu, Z., Tan, Y., Jin, Y., Liu, N., Hu, Y., Gu, S., Zhu, J. and Cui, Y. (2015) Nanopurification of Silicon From $84 \%$ to $99.999 \%$ Purity with a Simple and Scalable Process. Proceedings of the National Academy of Sciences, 112, 13473 13477. https://doi.org/10.1073/pnas.1513012112

[62] Taishi, T., Murao, Y., Ohno, Y. and Yonenaga, I. (2008) Segregation of Boron in Germanium Crystal. Journal of Crystal Growth, 311, 59-61. https://doi.org/10.1016/j.jcrysgro.2008.10.036

[63] Carcia, R. and Baez, A.P. (2012) Atomic Absorption Spectrometry. Techniques and Instrumentation in Analytical Chemistry, 5, 67-94.

[64] Chapon, P. Practical Comparisons Between RF-GD-OES and GDMS. Glow Discharge Optical Emission Spectroscopy, Technical Note 25, 1-2.

[65] Beske, H.E. (1981) Review and Evaluation of Spark Source Mass Spectrometry as an Analytical Method. Fresenius' Zeitschrift für analytische Chemie, 309, 329-341. https://doi.org/10.1007/BF00488613

[66] Curtolo, D., Friedrich, S., Bellin, D., Nayak, G. and Friedrich, B. (2017) Definition of a First Process Window for Purification of Aluminum via "Cooled Finger" Crystallization Technique. Metals (BaseI), 7, 341. https://doi.org/10.3390/met7090341

[67] Friedrich, S., Coladetti Curtolo, D. and Friedrich, B. (2017) Effect of Process Parameter Variation on Purity during Rotary Fractional Crystallization of Aluminum. Open Journal of Metal, 7, 25-38. https://doi.org/10.4236/ojmetal.2017.72003

[68] Zhu, T., Li, N., Mei, X., Yu, A. and Shang, S. (2001) Innovative Vacuum Distillation for Magnesium Recycling. Magnesium Technology 2001, John Wiley \& Sons, Inc., New York, 55-60. https://doi.org/10.1002/9781118805497.ch12

[69] Wang, Y.C., Tian, Y., Qu, T., Yang, B., Dai, Y.N. and Sun, Y.P. (2014) Purification of Magnesium by Vacuum Distillation and Its Analysis. Materials Science Forum, 788, 52-57. https://doi.org/10.4028/www.scientific.net/MSF.788.52

[70] Lam, R. and Marx, D.R. (1996) Ultra High Purity Magnesium Vacuum Distillation Purification Method. US5582630 A. https://www.google.com/patents/US5582630

[71] Tayama, K. and Kimura, S. (2003) Process and Apparatus for Producing High Purity Metals by Enhanced Purification. EP 1335030 A1.

[72] Löffler, J., Uggowitzer, P., Wegmann, C., Becker, M. and Feichtinger, H. (2013) Process and Apparatus for Vacuum Distillation of High-Purity Magnesium. WO2013107644 A1. 